\title{
Commentary: Having the right MINDset
}

\author{
Rizwan A. Manji, MD, PhD, MBA, and Rakesh C. Arora, MD, PhD
}

\footnotetext{
From the Section of Cardiac Surgery, Department of Surgery, Rady Faculty of Health Sciences, Max Rady College of Medicine, University of Manitoba, Winnipeg, Manitoba, Canada; and Cardiac Sciences Program, Winnipeg Regional Health Authority, Winnipeg, Manitoba, Canada.

Disclosures: Dr Arora has received an unrestricted educational grant from Pfizer Canada Inc and honoraria from Abbott Nutrition for work unrelated to this article. Dr Manji has nothing to disclose with regard to commercial support.

Received for publication April 1, 2019; accepted for publication April 2, 2019; available ahead of print May 22, 2019.

Address for reprints: Rizwan A. Manji, MD, PhD, MBA, I.H. Asper Clinical Research Institute, St Boniface Hospital, CR 3014-369 Tache Ave, Winnipeg, Manitoba R2H 2A6, Canada (E-mail: rmanji@sbgh.mb.ca).

J Thorac Cardiovasc Surg 2020;159:1901-2

$0022-5223 / \$ 36.00$

Copyright (C) 2019 by The American Association for Thoracic Surgery

https://doi.org/10.1016/j.jtcvs.2019.04.016
}

Delirium in critical illness has been associated with structural changes in the brain as demonstrated by imaging studies $^{1}$ and it carries significant consequences for patients, families, and the health care system resulting in $\$ 164$ billion/year in expenditures. ${ }^{2,3}$ Because delirium is associated with age, this burden is expected to increase as the baby boomer generation gets older. ${ }^{2,3}$ Because there are significant consequences of delirium, it is important to recognize delirium and treat reversible causes early to try and decrease some of the negative consequences.

Cardiac surgery and especially cardiac surgery intensive care unit (CSICU) patients are at high risk for delirium. ${ }^{4}$ Cha and Brown ${ }^{4}$ provide an excellent Invited Expert Opinion on delirium in CSICU patients who represented about $3 \%$ of the larger Modifying the Impact of ICUInduced Neurological Dysfunction-USA (MIND-USA) study. ${ }^{5}$ Cha and Brown ${ }^{4}$ conclude that antipsychotic medications do not appear to be effective in the treatment of hypoactive delirium in CSICU patients.

The MIND-USA study found that out of 566 mixed ICU patients, $89 \%$ had hypoactive delirium and that using either haloperidol or ziprasidone provided no shorter duration of delirium compared with placebo. ${ }^{5}$ A systematic review and meta-analysis of 48 studies including 27,342 patients found that hypoactive delirium was at least 4 times more prevalent than hyperactive delirium. ${ }^{2}$ However, despite hypoactive delirium being the most common form of delirium, studies show that $75 \%$ of hypoactive delirium cases are missed by clinicians, ${ }^{2}$ suggesting a significant barrier to timely identification and treatment of reversible etiologies of hypoactive delirium. Additionally, the MIND-USA study investigators noted that despite guidelines recommending against the use of antipsychotic medications for delirium, both hyper- and hypoactive delirium were frequently treated with antipsychotic medications.

If hypoactive delirium is so common, why is it so often missed and if recognized, why is it inappropriately treated system.

\section{References}

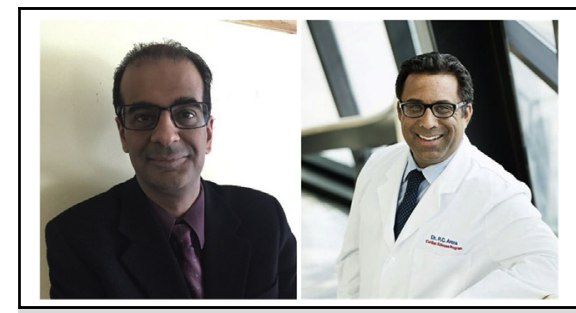

Rizwan A. Manji, MD, PhD, MBA, and Rakesh C. Arora, MD, PhD

\section{Central Message}

Cognitive biases such as framing may play an important role in missing the diagnosis of hypoactive delirium and in the inappropriate treatment of hypoactive delirium with antipsychotic medications.

See Article page 1895.

with antipsychotic medications? Misdiagnosis occurs frequently in medicine, with some studies suggesting occurrence in at least $20 \%$ of cases and much of this misdiagnosis is believed to be secondary to cognitive biases. ${ }^{6,7}$ Humans interpret information differently depending on mindset and indeed, there are studies showing variability in clinicians' ability to diagnose delirium. ${ }^{8}$ Perhaps hearing "delirium" gives one the picture of an agitated, aggressive patient (ie, hyperactive delirium) who needs antipsychotic medication to avoid harm to him- or herself or providers. ${ }^{2,9}$ Thus, if a positive delirium score is reported that patient gets an antipsychotic medication. On the other hand, slow, withdrawn, sedated, lethargic patients who may have hypoactive delirium are not considered delirious because they do not fit the picture of delirium that may be carried in one's mind. There is an increasing body of literature exploring the role of cognitive bias (eg, framing) in medical decision making. ${ }^{10}$ Perhaps the topic of cognitive bias is an area that needs to be further explored in delirium research to devise ways to have clinicians recognize hypoactive delirium and treat reversible causes quickly and appropriately to avoid the significant short- and long-term consequences to patients, families, and the health care

1. Morandi A, Rogers BP, Gunther ML, Merkle K, Pandharipande P, Girard TD, et al. The relationship between delirium duration, white matter integrity, and cognitive impairment in intensive care unit survivors as determined by diffusion 
tensor imaging: the VISIONS prospective cohort magnetic resonance imaging study. Crit Care Med. 2012;40:2182-9.

2. Krewulak KD, Stelfox HT, Leigh JP, Ely EW, Fiest KM. Incidence and prevalence of delirium subtypes in an adult ICU: a systematic review and meta-analysis. Crit Care Med. 2018;46:2029-35.

3. Haggstrom LR, Nelson JA, Wegner EA, Caplan GA. 2-18F-fluoro-2deoxyglucose positron emission tomography in delirium. J Cereb Blood Flow Metab. 2017:37:3556-67.

4. Cha S, Brown CH. Treating delirium in the intensive care unit: no easy answers. $J$ Thorac Cardiovasc Surg. 2020;159:1895-8.

5. Girard TD, Exline MC, Carson SS, Hough CL, Rock P, Gong MN, et al. Haloperidol and ziprasidone for treatment of delirium in critical illness. $N$ Engl J Med. 2018:379:2506-16
6. Singh H, Giardina TD, Meyer AN, Forjuoh SN, Reis MD, Thomas EJ. Types and origins of diagnostic errors in primary care settings. JAMA Intern Med. 2013;173: 418-25.

7. Berner ES, Graber ML. Overconfidence as a cause of diagnostic error in medicine. Am J Med. 2008;121(5 Suppl):S2-23.

8. Bhat R, Rockwood K. Inter-rater reliability of delirium rating scales. Neuroepidemiology. 2005;25:48-52.

9. Devlin JW, Skrobik Y, Gélinas C, Needham DM, Slooter AJC, Pandharipande PP, et al. Clinical practice guidelines for the prevention and management of pain, agitation/sedation, delirium, immobility, and sleep disruption in adult patients in the ICU. Crit Care Med. 2018;46:e825-73.

10. Saposnik G, Redelmeier D, Ruff CC, Tobler PN. Cognitive biases associated with medical decisions: a systematic review. BMC Med Inform Decis Mak. 2016;16:138. 